\title{
PROVISIONS FOR THE CARE OF CHILDREN OF DIVORCED PARENTS: A NEW LEGAL INSTRUMENT
}

\author{
LAWRENCE S. KUBIE, M.D. $\dagger$
}

THERE is clear evidence that longevity is one of the major causes of the increasing incidence of divorce. ${ }^{1}$ Concurrently there has been a sharp drop in the mortality rate in childhood and adolescence. As a consequence of these simultaneous changes, increasing numbers of minor children have divorced parents and for more years. The law must deal with these increasing numbers flexibly. It may be necessary, therefore, to develop new legal instruments for the protection of the interests of the children of divorced parents.

In Ford v. Ford, ${ }^{2}$ decided by the U.S. Supreme Court in $1962, \mathrm{Mr}$. Justice Black wrote, "Unfortunately, experience has shown that the question of custody, so vital to a child's happiness and well-being, frequently cannot be left to the discretion of the parents. This is particularly true where, as here, the estrangement of husband and wife beclouds parental judgment with emotion and prejudice."3

When a marriage fails, the usual procedure for providing for the welfare of children, whether created by private agreement or by a battle in court, is either to award exclusive custody to one parent, or to divide custody between parents at some specified intervals in time, such as vacations, holidays, etc., or to entrust custody to a court-appointed guardian. Usually, however, a court-appointed guardian is viewed as a last resort, because it does not meet the child's need for parents; the other usual dispositions are rigid, and can be altered only by the complicated process of adjudication.

Since the needs of children change during the years before they reach maturity, whatever provisions the law makes for them should be flexible. Yet the many combinations of provisions which are ordinarily incorporated in separation agreements and divorce papers have three inflexible attributes in common: (a) an effort to achieve a compromise between the demands and feelings of contending parents; (b) an absence of any machinery first for discovering and then for serving the changing needs of the child; and (c) a built-in tendency to be less flexible than a child's welfare requires.

No one can foresee the future. Therefore the usual provisions can have at best an accidental relationship to the emotional needs of children as these change over the years. There may be times when a child needs the constant attention and affection of his mother, others when his father's masculine image

$†$ Director of Training, Sheppard and Enoch Pratt Hospital, Towson, Maryland.

1. Jacobson, Anterican Marriage and Divorce (1959); Kubie, The Disintegrating Impact of "Madern" Life on the Family in America and Its Explosive Repercussions, in Liebaran (ed.), Emotional Forces in the Fairily 157 (1959).

2. 371 U.S. 187 (1962).

3. 371 U.S. at 193. 
is of primary importance. Furthermore not only the child but the parents and their relationships may change. One or the other may marry or become ill. Such changes create new emotional needs in the child. Although courts can and do change custody provisions in efforts to meet changing needs, parents are reluctant to invoke the machinery of the law for this purpose unless there are overwhelming reasons for doing so, because the judicial machinery is slow and expensive and may involve a degree of publicity which in itself is damaging to the children and undesirable for the parents.

In order to provide a satisfactory compromise between the parents and to gain that flexibility which is necessary for the child, it is necessary to develop new legal instruments for the protection of the interests of the children of divorced parents. Such a new approach is surely conceivable; but since I am not a lawyer, my only right to claim that the following suggestion is feasible derives from the fact that it has already been incorporated into a large number of separation and divorce agreements, which have been drawn up by eminent law firms in several states. The essence of the proposal consists of joint custody of the child, the appointment of a confidential adult-ally for the child and a committee chosen by the parents to decide questions on which the parents are unable to agree.

The specific steps are as follows. Upon separation or divorce the parents agree that the child's interests are paramount, and that neither of them shall have an exclusive right to custody. They accept the responsibility to attempt to decide together by mutual agreement every question that has a bearing on the welfare of their child or children, e.g., where the child shall live and with whom and for how long, where the child shall go to school and the kind of school, what kind of medical or psychological help the child may have if needed, what kind of vacations to spend and where and with whom, etc.

If and whenever the parents cannot reach an agreement on any matter of concern to the child, they agree to submit the issue to a committee which they themselves choose at the time they make the agreement, and to accept unconditionally the committee's decisions, and to be guided by it. The committee will act at the instance of either parent, and the failure of the other to present his side when given the opportunity does not make the committee's decision ineffective.

(There are arguments for the relative simplicity of choosing a single individual for this task rather than a committee; but in practice it has proved almost impossible to persuade any one individual to carry so heavy a responsibility alone, and relatively easy to persuade even the same individual to serve on a committee. Furthermore, the committee offers a degree of continuity, stability and weight of authority which no one individual can supply.)

The parents select the members of this committee by mutual agreement, and directly or through their respective counsel secure the necessary consents to serve. It is usual to ask a pediatrician, a child psychiatrist or child analyst, an educator and/or an impartial lawyer or clergyman. The parents grant to the members of the committee the right to replace any member who with- 
draws or becomes ill or dies; but in choosing such a replacement the committee must have its choice approved by the two principals, or where necessary by their respective legal advisors.

The parents further agree that each child shall have one trusted adult-ally outside the family circle with whom the child can talk in confidence. They choose this person from a list of available certified specialists in child psychology, child psychiatry or child analysis. The purpose of this is to make sure that someone who has experience with the highly specialized skills of interviewing and drawing out children will always be available to explore in confidence the child's reactions to parents, homes, schools, camps, doctors and all similar factors for the guidance of both the parents and the committee. It is rarely easy for a child to talk to adults, and least of all to his own warring parents. Under these circumstances, to talk to either will make a child feel disloyal to the other. He will be able to talk to an adult-ally who is outside of the family without this inhibiting restriction. As already indicated, such an adult-ally should have had technical training and experience in the highly specialized art of listening to children. Given such training, he can then inform the committee of what the child thinks and feels, thus providing a sound basis for the committee's decisions.

Finally, the agreement stipulates that the committee will have no role in the financial guardianship of the children, but will deal only with their spiritual, educational and psychological welfare and general health. It is obvious that it will have to confer at times with the financial guardians of the child concerning the economic feasibility of its recommendations.

The advantage of this proposal is that primary emphasis is placed on discovering and serving the child's changing needs. As those needs change, at least one of the parents will presumably perceive the change, and either persuade the other or bring the problem before the committe which, aided by the child's ally, will be able to evaluate the situation free from the parents' biases. Adjustments can thus be made without publicity, controversy or great expense. The child will also have the psychological advantage of retaining active contact with both parents. Unless one or the other parent has been flagrantly brutal and destructively amoral in relation to the child (in which case the other parent presumably would not enter into such an agreement in the first place), it is always disturbing to children to be substantially removed from contact with either parent; because this gives rise to a secret feeling that there are first-class and second-class parents. The difficulties which this feeling produces can be traced through later years and even into the ultimate marriages of these children. Therefore, a framework within which both parents maintain contact and can work in harmony is psychologically of value to the child. Continuing relationship with both parents has been available in limited measure through the customary provisions for joint custody, but the lack of adequate machinery for resolving disagreements has often rendered joint custody impractical and has led to the disruption of the relationship of the child to one parent or the other. It is this mechanism which the committee provides. 
No individual and no committee can hope for the wisdom of Solomon. One need not expect that no mistakes of judgment will occur. Yet it is likely that the committee will arrive at wise conclusions more consistently than the parent. No parent can evaluate his own children's needs apart from his own feelings. No matter how sophisticated, mature and generous the parents may be, each must in some measure have an axe to grind. A committee of friendly outsiders provides not only special competence, but also an essential degree of objectivity. The likelihood of sound decisions is still further increased by the fact that they can benefit by the information and the counsel offered by the special adult-ally of the child, for which the agreement provides.

In practice, such committees have done more than solve disputes. Their mere existence often protects the parents from reaching an impasse. As a result, such committees have had to be called into action only rarely. I have seen parents who had squabbled for years behave with restraint and generosity under the civilizing influence of the externalized conscience which the committee comes to represent. Furthermore the parents will have chosen the committee from among people they both know and respect; and they will be ashamed to appear before it to admit that they have failed to reach agreement. Nor will a parent lightly reject the decision of a committee after the committee has been called into action, both because of the high moral force which the committee represents, and because of the new problems which such a rejection would initiate. I have only once seen a parent even attempt to reject a committee's decision.

At this point, lawyers usually ask whether a court, which has of course the right to scrutinize committee decisions, would accept the committee device and enforce its decisions. I cannot answer this question, because to the best of my knowledge it has never been tested. However, since such a plan as this is intrinsically fair to both parents, since it places consideration of the welfare of the child above the pride of parents, since it has been entered into freely by the parents, and since the committee will have considerable competence, any parent who rejects the decision of a committee would come into court with a case which was strongly weighted against him. Certainly no better machinery is available to any court for determining a child's best interests, than is available to the committee with the aid of the child's specially qualified ally. 